\title{
Epidemiologia de neoplasias em pessoas vivendo com HIV/AIDS
}

\author{
Epidemiology of neoplasms in people living with HIV/AIDS \\ Epidemiología de las neoplasias en personas que viven con el VIH/SIDA
}

Recebido: 09/08/2021 | Revisado: 15/08/2021 | Aceito: 20/08/2021 | Publicado: 22/08/2021

\author{
José Albano Tenório de Moura Filho \\ ORCID: https://orcid.org/0000-0002-4159-6854 \\ Universidade Católica de Pernambuco, Brasil \\ E-mail: albano1704@gmail.com \\ Carlos Alberto Tenório de Araújo III \\ ORCID: https://orcid.org/0000-0002-6718-4823 \\ Universidade Católica de Pernambuco, Brasil \\ E-mail: carlosalbertotenorioiii@gmail.com \\ Nadja Maria Jorge Asano \\ ORCID: https://orcid.org/0000-0003-3644-7333 \\ Universidade Católica de Pernambuco, Brasil \\ E-mail: nadjaasano@hotmail.com \\ Manuela Barbosa Rodrigues de Souza \\ ORCID: https://orcid.org/0000-0002-7773-100X \\ Universidade Católica de Pernambuco, Brasil \\ E-mail: manu.brsouza@gmail.com
}

\begin{abstract}
Resumo
As alterações do sistema imunológico causadas pelo HIV caracterizam a Síndrome de Imunodeficiência Adquirida (AIDS), a qual suscetibiliza o organismo do hospedeiro à agressão de agentes exógenos, proporcionando infecções oportunistas por cepas oncogênicas. São escassas as pesquisas que abordam a questão das neoplasias associadas ao HIV, o que torna importante esta revisão com o objetivo de abordar os fatores epidemiológicos da relação entre neoplasias e HIV. O estudo trata-se de uma revisão integrativa de publicações entre o período de 2009 a 2019, disponibilizados em português e inglês. Foi realizado um levantamento nas bases de dados Lilacs, PubMed e SciELO. Para analisar qualidade metodológica, utilizou-se o Critical Appraisal Skill Programme (CASP) adaptado e o Agency for Healthcare and Research and Quality (AHRQ) adaptado. O linfoma não-Hodgkin (NHL), o sarcoma de Kaposi (SK) e o carcinoma de colo uterino invasivo apresentaram os maiores índices de prevalência como neoplasias mais frequentes em indivíduos vivendo com o HIV/aids, consideradas definidoras da AIDS. Além disso, o gênero masculino e a raça caucasiana foram as mais relacionados com o desenvolvimento de neoplasias em pessoas que vivem com HIV/AIDS.
\end{abstract}

Palavras-chave: Síndrome de Imunodeficiência Adquirida; Epidemiologia; Sarcoma de Kaposi; Linfoma não Hodgkin; Neoplasias do Colo do Útero.

\begin{abstract}
Changes in the immune system caused by HIV characterize the Acquired Immune Deficiency Syndrome (AIDS), which makes the host's organism susceptible to aggression from exogenous agents, providing opportunistic infections by oncogenic strains. There are few studies that address the issue of cancers associated with HIV, which makes this review important to address the epidemiological factors of the relationship between cancer and HIV. The study is an integrative review of publications from 2009 to 2019, available in Portuguese and English. The search was carried out in Lilacs, PubMed and SciELO databases. To analyze the methodological quality, the adapted Critical Appraisal Skill Program (CASP) and the adapted Agency for Healthcare and Research and Quality (AHRQ) were used. NonHodgkin's lymphoma (NHL), Kaposi's sarcoma (KS) and invasive cervical carcinoma have the highest prevalence rates as the most frequent neoplasms in HIV/AIDS prevalent, considered to define AIDS. In addition, male gender and white race were the most related to the development of neoplasms in people living with HIV/AIDS.
\end{abstract}

Keywords: Acquired Immunodeficiency Syndrome; Epidemiology; Kaposi's sarcoma; Non-Hodgkin's lymphoma; Cervical Neoplasms.

\section{Resumen}

Los cambios en el sistema inmunológico provocados por el VIH caracterizan al Síndrome de Inmunodeficiencia Adquirida (SIDA), que hace que el organismo del huésped sea susceptible a la agresión de agentes exógenos, proporcionando infecciones oportunistas por cepas oncogénicas. Hay pocos estudios que aborden el tema de los cánceres asociados con el VIH, lo que hace que esta revisión sea importante para abordar los factores epidemiológicos 
de la relación entre el cáncer y el VIH. El estudio es una revisión integradora de publicaciones de 2009 a 2019 , disponible en portugués e inglés. La búsqueda se realizó en las bases de datos Lilacs, PubMed y SciELO. Para analizar la calidad metodológica, se utilizó el Programa de Habilidad de Valoración Crítica (CASP) adaptado y la Agencia de Investigación y Calidad de la Salud y la Calidad (AHRQ) adaptada. El linfoma no Hodgkin (LNH), el sarcoma de Kaposi (SK) y el carcinoma cervical invasivo tienen las tasas de prevalencia más altas como las neoplasias más frecuentes de prevalencia del VIH/SIDA, consideradas para definir el SIDA. Además, el género masculino y la raza blanca fueron los más relacionados con el desarrollo de neoplasias en personas que viven con VIH/SIDA.

Palabras chave: Síndrome de Inmunodeficiencia Adquirida; Epidemiología; Sarcoma de Kaposi; Linfoma no Hodgkin; Neoplasias cervicales.

\section{Introdução}

O Vírus da Imunodeficiência Humana (HIV) é um retrovírus humano não transformador que pertence à subfamília Lentiviridae. Além disso, ele é composto por um envoltório lipídico derivado da membrana do hospedeiro, duas fitas de RNA idênticas não complementares, três enzimas virais (protease, transcriptase reversa e integrase) e proteínas, como a p24, p7, p9. Há duas formas do vírus: o tipo HIV-1 e o HIV-2, sendo o primeiro presente nos Estados Unidos, África Central e Europa, enquanto o segundo predomina mais na Índia e no Oeste da África. A transmissão do HIV ocorre sob condições que facilitam a troca de sangue ou líquidos corporais que possuem o vírus ou células infectadas. O contato sexual, a transmissão vertical e a inoculação parenteral são as três principais vias de transmissão, sendo a primeira via a mais predominante (Robbins, 2010).

O HIV atua diretamente no sistema imune, destruindo as células CD4+, também conhecidas como linfócitos T auxiliares. Em decorrência, há o desequilíbrio das respostas imunológicas naturais e adquiridas, uma vez que não haverá a liberação de citocinas, responsáveis pela ativação do sistema fagocitário, dos linfócitos B e outros leucócitos, como os monócitos (Caetano, 1991).

As alterações do sistema imunológico causadas pelo HIV caracterizam a Síndrome de Imunodeficiência Adquirida (AIDS), deixando o organismo do hospedeiro exposto à agressão de agentes exógenos, proporcionando infecções oportunistas por cepas oncogênicas, como o Papilomavírus Humano (HPV). O Papilomavírus humano (HPV) pertence à família Papillomaviridae, subfamília Papilomavirinae e ao gênero Papillomavirus. O HPV apresenta-se protegido por uma capa proteica, o capsídeo, o qual comporta a dupla fita de DNA circular em estrutura helicoidal (Burd, 2003).

Esse vírus possui mais de 100 genótipos diferentes descritos até o momento e aproximadamente 35 genótipos são encontrados na região anogenital (Bosch et al., 2002). Ademais, o HPV apresenta uma via de transmissão em comum com o HIV, a via sexual. Mulheres que vivem com o HIV/aids são 5 vezes mais propensas à infecção concomitante pelo HPV, visto que, os seus sistemas imunitários encontram-se debilitados, tornando-as mais susceptíveis à infecção por múltiplos vírus HPV. Por apresentarem menor capacidade de eliminar os vírus, estas mulheres apresentam maior persistência da lesão e evolução para cancro cervical. Apesar da introdução terapêutica antirretroviral (TAR) diminuir a incidência de sarcoma de Kaposi e de Linfoma Hodgkin, não reduz a incidência de cancro cervical (Sardinha et al., 2015).

Dessa forma, é importante que haja o diagnóstico precoce do HPV e outras neoplasias em pacientes vivendo com HIV/aids, a fim de reduzir os danos e sequelas irreversíveis. Diversas comorbidades associadas à infecção do HIV tem uma importância fundamental no tratamento do paciente. Portanto, maiores informações dessas comorbidades para os gestores criará uma estratégia de atendimento para essa população, aumentando qualidade de vida e reduzindo a incidência de sequelas e óbitos.

O estudo tem como objetivo analisar a produção científica relacionada a epidemiologia de neoplasias em pessoas vivendo com HIV/AIDS. 


\section{Metodologia}

Trata-se de uma revisão integrativa, a qual permitiu a busca, avaliação crítica e síntese das evidências disponíveis sobre um delimitado tema ou questão norteadora, contribuindo para a prática baseada em evidência na saúde. Foram utilizadas seis etapas metodológicas: 1- identificação do tema e seleção da questão norteadora da pesquisa; 2- estabelecimento de critérios para inclusão e exclusão dos estudos; 3- definição das informações a serem extraídas dos estudos selecionados e categorização destes; 4- avaliação dos estudos incluídos na revisão; 5- interpretação dos resultados; 6- apresentação da revisão e síntese do conhecimento.

Para a primeira etapa foi elaborada a seguinte questão norteadora: Quais as evidências científicas publicadas no período de 2009 a 2019 sobre a epidemiologia de neoplasias em pessoas vivendo com HIV/AIDS. Em seguida, estabeleceramse critérios de elegibilidade para obtenção e seleção dos artigos por meio de busca, entre maio e junho de 2019, nas bases de dados LILACS (Literatura Latino-Americana e do Caribe em Ciências da Saúde), PubMed (U.S. National Library of Medicine) e sciELO (Scientific Electronic Library Online). Os artigos incluídos deveriam tratar de abordagens que se relacionam com o tema, terem sido publicados entre os anos de 2009 e 2019, disponibilizados em português, inglês e espanhol. Não houve restrição quanto ao desenho de estudo. Foram excluídos estudos repetidos em bases de dados e que não contemplavam o tema. Para a busca dos artigos foram utilizadas palavras-chave indexadas aos Descritores em Ciências da Saúde (DeCS) - “Aids”, "Epidemiologia"," Neoplasia". O operador booleano de escolha foi o AND.

Para análise metodológica dos artigos incluídos foram aplicados: 1) instrumento adaptado do Critical Appraisal Skill Programme (CASP) e 2) Agency for Healthcare and Research and Quality (AHRQ). O CASP adaptado contempla 10 itens a serem pontuados: 1) objetivo claro e justificado; 2) metodologia adequada; 3) apresentação e discussão dos procedimentos teóricos e metodológicos; 4) seleção adequada da amostra; 5) coleta de dados detalhada; 6) relação entre pesquisador e pesquisados; 7) aspectos éticos preservados; 8) análise de dados rigorosa e fundamentada; 9) apresentação e discussão dos resultados e 10) contribuições, limitações e indicações de novas questões de pesquisa. Para cada item foi atribuído o valor 0 (zero) ou 1 (um), sendo o total a soma das pontuações, cujo escore máximo é de 10 pontos. Os artigos selecionados foram classificados conforme as pontuações: nível A - 6 a 10 pontos (boa qualidade metodológica e viés reduzido) ou nível B - no mínimo 5 pontos (qualidade metodológica satisfatória, porém com risco de viés aumentado).

O AHRQ classifica estudos em oito níveis conforme o nível de evidência: I) revisão sistemática ou metanálise; II) ensaios clínicos randomizados; III) estudo ecológico exploratório; IV) coorte e caso-controle; V) revisão da literatura; VI) estudo transversal VII) opinião de autoridades e/ou relatório de comitês de especialidades; VIII) estudo quantitativo e qualitativo.

\section{Resultados}

Dos 95 artigos encontrados, 45 não atenderam ao critério de inclusão "ano de publicação", 19 ao "idioma" e 16 à pergunta condutora, culminando em 15 artigos. Destes 15, 02 estavam repetidos, resultando em 13 artigos na amostra final (Figura 1). As principais informações da amostra final encontram-se no Quadro 1. Quanto ao idioma, 10 artigos (76,92\%) foram publicados em inglês, 03 (23,07\%) em português. Também, 05 (38,46\%) eram de revistas nacionais e 08 (61,53\%) de revistas internacionais. Dos anos de publicação, 01 artigo de 2018 (7,69\%), seguido por 01 de 2017 (7,69\%), 01 de 2016 (7,69\%), 02 de 2015 (15,38\%), 01 de 2014 (7,69\%), 02 de 2012 (15,38\%), 03 de 2011 (23,07\%) e 01 de 2009 (7,69\%). Acerca dos países: 06 foram realizados no Brasil (46,15\%), 02 na Colômbia (15,38\%), 02 nos Estados Unidos (15,38\%), 01 na Itália (7,69\%), 01 na França (7,69\%) e 01 no Japão (7,69\%).. Após leitura na íntegra dos estudos, 13 (100\%) foram classificados como nível A e nenhum (0\%) como nível B, conforme CASP adaptado. Através do AHRQ, 07 artigos (53,84\%) foram 
Research, Society and Development, v. 10, n. 11, e48101119240, 2021

(CC BY 4.0) | ISSN 2525-3409 | DOI: http://dx.doi.org/10.33448/rsd-v10i11.19240

classificados como nível IV de evidência, por serem estudos Coortes ou Caso-controles, 03 (23,07\%) como nível VI, 01 (7,69\%) como nível I, 01 (7,69\%) como nível III e 01 (7,69\%) como nível V.

Figura 1. Fluxograma de demonstração da amostra final.

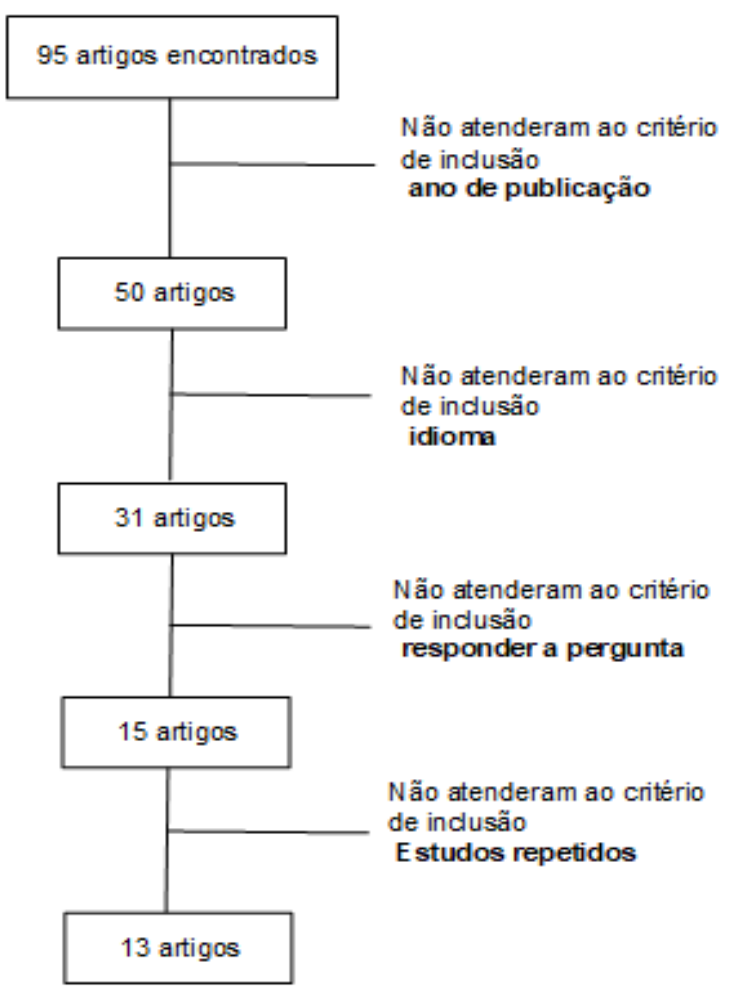

Fonte: Autores (2021). 
Quadro 1. Descrição sintetizada e níveis de evidência, segundo CASP adaptado e AHRQ, de cada estudo que compôs a revisão. Recife-PE, 2021.

\begin{tabular}{|c|c|c|c|c|c|c|c|}
\hline $\begin{array}{l}\text { Autor, } \\
\text { ano }\end{array}$ & $\begin{array}{l}\text { País do } \\
\text { estudo }\end{array}$ & $\begin{array}{l}\text { Desenho do } \\
\text { estudo }\end{array}$ & Amostra & Objetivo & Principais achados & $\begin{array}{c}\text { Evidência } \\
\text { (CASP) } \\
\text { adaptado }\end{array}$ & $\begin{array}{c}\text { Evidência } \\
\text { AHRQ }\end{array}$ \\
\hline $\begin{array}{l}\text { Ceccato } \\
\text { Junior et } \\
\text { al., } 2015\end{array}$ & Brasil & Transversal & $\begin{array}{lr}697 \text { pacientes, } \\
\text { sendo } \quad 366 \\
\text { para avaliar } \\
\text { NIC e } 331, \\
\text { HPV }\end{array}$ & $\begin{array}{l}\text { Realizar } \begin{array}{r}\text { estudo } \\
\text { comparativo entre }\end{array} \\
\text { mulheres positivas e } \\
\text { negativas para o HIV, } \\
\text { analisando: } \\
\text { prevalência de NIC e } \\
\text { HPV; risco viral e } \\
\text { relação rom } \\
\text { desenvolvimento de } \\
\text { NIC; parâmetros } \\
\text { sociodemográficos e } \\
\text { de comportamento } \\
\text { que influenciaram na } \\
\text { presença de infecção } \\
\text { cervical por HPV e } \\
\text { NIC. }\end{array}$ & $\begin{array}{l}\text { A prevalência de NIC e infecção } \\
\text { cervical pelo HPV foi maior nas } \\
\text { mulheres positivas para o HIV, } \\
\text { que também apresentaram mais } \\
\text { infecções por HPV de alto risco e } \\
\text { múltiplos tipos. O tipo } 16 \text { foi o } \\
\text { predominante nos dois grupos e } \\
\text { nas mulheres que tiveram NIC. } \\
\text { Mulheres com mais idade e em } \\
\text { união estável/viúvas tiveram } \\
\text { menor chance de adquirir infecção } \\
\text { cervical por HPV ou NIC. } \\
\text { Mulheres com múltiplos parceiros } \\
\text { sexuais tiveram mais chances de } \\
\text { adquirir infecção cervical pelo } \\
\text { HPV. }\end{array}$ & $\bar{A}$ & VI \\
\hline $\begin{array}{l}\text { Nagata } e t \\
\text { al., } 2018\end{array}$ & Japão & $\begin{array}{l}\text { Coorte } \\
\text { retrospectivo }\end{array}$ & $\begin{array}{l}1001 \\
\text { pacientes }\end{array}$ & $\begin{array}{l}\text { Elucidar a incidência } \\
\text { de NADC's e seus } \\
\text { fatores preditivos em } \\
\text { pacientes asiáticos } \\
\text { infectados pelo HIV. }\end{array}$ & $\begin{array}{l}\text { O risco de câncer de fígado e } \\
\text { cólon foi alto em pessoas asiáticas } \\
\text { vivendo com HIV, semelhante às } \\
\text { populações ocidentais, já o risco } \\
\text { de câncer de estômago foi maior } \\
\text { nos asiáticos. Metade dos } \\
\text { pacientes com NADC tinha entre } \\
40 \text { e } 59 \text { anos e apresentava doença } \\
\text { em estágio avançado no } \\
\text { diagnóstico. }\end{array}$ & $\mathrm{A}$ & IV \\
\hline $\begin{array}{l}\text { Ceccato } \\
\text { Junior } \\
\text { al., } 2016\end{array}$ & Brasil & Coorte & 216 pacientes & $\begin{array}{l}\text { Avaliar a incidência e } \\
\text { fatores associados } \\
\text { com (NIC) e (HPV) } \\
\text { entre mulheres HIV } \\
\text { positivas e negativas. }\end{array}$ & $\begin{array}{l}\text { Mulheres vivendo com HIV têm } \\
\text { maior incidência de NIC e } \\
\text { desenvolvem lesões em um } \\
\text { intervalo mais curto. Mulheres } \\
\text { jovens e fora de um } \\
\text { relacionamento estável têm maior } \\
\text { chance de desenvolver neoplasia. } \\
\text { A incidência de infecção pelo } \\
\text { HPV foi semelhante entre os dois } \\
\text { grupos de estudo, mas a presença } \\
\text { do vírus foi detectada mais cedo } \\
\text { em mulheres vivendo com HIV. }\end{array}$ & A & IV \\
\hline $\begin{array}{l}\text { Freitas et } \\
\text { al., } 2017\end{array}$ & Brasil & caso-controle & 81 pacientes & $\begin{array}{l}\text { Avaliar o perfil } \\
\text { epidemiológico dos } \\
\text { pacientes infectados } \\
\text { pelo HIV com câncer; } \\
\text { comparar as } \\
\text { características } \\
\text { epidemiológicas, } \\
\text { clínicas e o desfecho } \\
\text { clínico dos pacientes } \\
\text { infectados pelo HIV } \\
\text { com e sem câncer. }\end{array}$ & $\begin{array}{l}\text { Nas duas populações estudadas } \\
\text { (HIV com câncer e HIV sem } \\
\text { câncer) predominou o sexo } \\
\text { masculino, a raça branca e a faixa } \\
\text { etária de } 40 \text { a } 50 \text { anos (mediana de } \\
46 \text { anos). Dos infectados pelo HIV } \\
\text { e com câncer, } 55,5 \% \text { dos cânceres } \\
\text { foram do tipo "definidores de } \\
\text { AIDS" e } 44,5 \% \text {, não relacionados } \\
\text { à AIDS. Foi encontrado um maior } \\
\text { número de LNH e o SK } \\
\text { relacionados ao HIV. }\end{array}$ & $\overline{\mathrm{A}}$ & IV \\
\hline
\end{tabular}




\begin{tabular}{|c|c|c|c|c|c|c|c|}
\hline $\begin{array}{l}\text { Nahas et } \\
\text { al., } 2011\end{array}$ & Brasil & $\begin{array}{c}\text { revisão da } \\
\text { literatura }\end{array}$ & $\begin{array}{c}250 \\
\text { indivíduos }\end{array}$ & $\begin{array}{l}\begin{array}{l}\text { Avaliar a correlação } \\
\text { entre } \\
\text { lesões }\end{array} \\
\text { precursoras } \\
\text { carcinoma do } \\
\text { espinocelular anal e } \\
\text { indivíduos portadores } \\
\text { do HIV, através do } \\
\text { rastreamento. }\end{array}$ & $\begin{array}{l}\text { viver com HIV é um grande fator } \\
\text { de risco no desenvolvimento de } \\
\text { CEC anal em indivíduos } \\
\text { infectados por HPV. } \\
\text { A diminuição da resposta imune, } \\
\text { devido a diminuição de células } \\
\text { CD4+, facilitam a multiplicação } \\
\text { viral e permitem o aparecimento } \\
\text { de lesões mais graves que podem } \\
\text { evoluir para displasia e câncer. }\end{array}$ & A & $\mathrm{V}$ \\
\hline $\begin{array}{l}\text { Micheletti } \\
\text { et al., } 2011\end{array}$ & Brasil & caso controle & $\begin{array}{c}261 \\
\text { necropsias }\end{array}$ & $\begin{array}{l}\text { Analisar a frequência } \\
\text { de neoplasias } \\
\text { benignas e malignas } \\
\text { em pacientes vivendo } \\
\text { com HIV/aids nos } \\
\text { períodos de pré e pós- } \\
\text { HAART. }\end{array}$ & $\begin{array}{l}\text { Os tipos de neoplasia mais } \\
\text { encontrados em necropsias de } \\
\text { pacientes que viviam com HIV } \\
\text { foram SK e LNH, que são } \\
\text { conhecidamente associados à } \\
\text { AIDS. }\end{array}$ & A & IV \\
\hline $\begin{array}{l}\text { Saldariaga- } \\
\text { Cantillo et } \\
\text { al., } 2012\end{array}$ & $\begin{array}{c}\text { Colômbi } \\
\text { a }\end{array}$ & $\begin{array}{l}\text { Estudo } \\
\text { ecológico } \\
\text { exploratório }\end{array}$ & 349 casos & $\begin{array}{l}\text { Investigar } \\
\text { tendências das taxas } \\
\text { de incidência do SK } \\
\text { antes e durante a } \\
\text { epidemia (HIV / } \\
\text { AIDS) em Cali, } \\
\text { Colômbia. }\end{array}$ & $\begin{array}{l}\text { Houve uma diminuição } \\
\text { significativa na proporção de } \\
\text { mulheres, } \\
\text { influenciada por fatores protetivos } \\
\text { presentes nesse sexo, que podem } \\
\text { diminuir o risco de desenvolver } \\
\text { SK. }\end{array}$ & A & III \\
\hline $\begin{array}{l}\text { Pinto Neto } \\
\text { et al., } 2012\end{array}$ & Brasil & Transversal & 730 pacientes & $\begin{array}{l}\text { Relatar a prevalência } \\
\text { de câncer e seus } \\
\text { fatores associados em } \\
\text { indivíduos vivendo } \\
\text { com } r \text { HIV/aids } \\
\text { atendidos em um } \\
\text { ambulatório de AIDS } \\
\text { em Vitória, Espírito } \\
\text { Santo, Brasil. }\end{array}$ & $\begin{array}{l}\text { Pacientes vivendo com HIV e } \\
\text { com câncer apresentam pior } \\
\text { prognóstico e estão vindo a óbito } \\
\text { mais cedo se comparados aos } \\
\text { pacientes vivendo com HIV, mas } \\
\text { sem câncer. Há controvérsias } \\
\text { sobre a incidência de câncer de } \\
\text { próstata e colorretal em pessoas } \\
\text { com AIDS. Vários relatos } \\
\text { sugerem menor risco para esses } \\
\text { tipos de câncer entre pessoas } \\
\text { infectadas pelo HIV, porém, } \\
\text { Shiels et al. observaram um } \\
\text { aumento na incidência de câncer } \\
\text { de próstata na população infectada } \\
\text { pelo HIV nos EUA. }\end{array}$ & A & $\mathrm{VI}$ \\
\hline $\begin{array}{l}\text { Raffetti et } \\
\text { al., } 2015\end{array}$ & Itália & $\begin{array}{c}\text { Coorte } \\
\text { retrospectivo }\end{array}$ & $\begin{array}{c}16.268 \\
\text { pacientes }\end{array}$ & $\begin{array}{l}\text { Avaliar a incidência e } \\
\text { mortalidade por } \\
\text { câncer por todas as } \\
\text { causas e fatores } \\
\text { relacionados ao risco } \\
\text { de morte em uma } \\
\text { coorte italiana de } \\
\text { pacientes não } \\
\text { selecionados } \\
\text { infectados pelo HIV, } \\
\text { em comparação com a } \\
\text { população em geral. }\end{array}$ & $\begin{array}{l}\text { Em pacientes vivendo com HIV, } \\
\text { a incidência de ADCs foi maior } \\
\text { que na população em geral, o que } \\
\text { não ocorreu nos NADCs. Embora } \\
\text { a mortalidade geral em indivíduos } \\
\text { HIV + tenha diminuído com o } \\
\text { tempo, ainda é cerca de três vezes } \\
\text { maior que a população geral no } \\
\text { ano do estudo. }\end{array}$ & $\mathrm{A}$ & IV \\
\hline $\begin{array}{l}\text { Hleyhel et } \\
\text { al., } 2014\end{array}$ & França & Coorte & $\begin{array}{c}84.504 \\
\text { pacientes }\end{array}$ & $\begin{array}{l}\text { Avaliar a incidência e } \\
\text { as tendências de risco } \\
\text { de câncer de pulmão, } \\
\text { linfoma de Hodgkin, } \\
\text { câncer de fígado e } \\
\text { anal, com foco em } \\
\text { pacientes com } \\
\text { recuperação de células } \\
\text { CD4 + e idade ao } \\
\text { diagnóstico, em } \\
\text { comparação com a } \\
\text { população em geral. }\end{array}$ & $\begin{array}{l}\text { Entre } 1997 \text { e } 2009 \text {, o risco dos } \\
\text { quatro NADCs estudados (sendo o } \\
\text { de pulmão o mais frequente, } \\
\text { seguido pelo LH e o de fígado } \\
\text { respectivamente) permaneceu } \\
\text { muito maior nos indivíduos } \\
\text { vivendo com o HIV do que na } \\
\text { população em geral. }\end{array}$ & $\mathrm{A}$ & IV \\
\hline
\end{tabular}




\begin{tabular}{|c|c|c|c|c|c|c|c|}
\hline $\begin{array}{l}\text { Silverberg } \\
\text { et al., } 2009\end{array}$ & $\begin{array}{l}\text { Estados } \\
\text { Unidos }\end{array}$ & $\begin{array}{l}\text { Coorte } \\
\text { retrospectivo }\end{array}$ & 222.590 & $\begin{array}{l}\text { Avaliar } \text { o risco de } \\
\text { câncer com e sem } \\
\text { causa } \\
\text { conhecida em pessoas } \\
\text { infectadas pelo HIV. }\end{array}$ & $\begin{array}{l}\text { As pessoas vivendo com HIV } \\
\text { tiveram um risco aumentado em } \\
\text { mais de nove vezes de NADC em } \\
\text { comparação com as pessoas HIV } \\
\text { negativas. As HIV+ também } \\
\text { tiveram um risco } 30 \% \text { maior de } \\
\text { NADCs não relacionado à } \\
\text { infecção em comparação com as } \\
\text { pessoas não infectadas pelo HIV. } \\
\text { Por fim, cerca de } 70 \% \text { dos } \\
\text { cânceres em pessoas vivendo com } \\
\text { HIV têm uma causa infecciosa } \\
\text { conhecida. }\end{array}$ & A & IV \\
\hline $\begin{array}{l}\text { Shiels et } \\
\text { al., } 2011\end{array}$ & $\begin{array}{l}\text { Estados } \\
\text { Unidos }\end{array}$ & $\begin{array}{c}\text { revisão } \\
\text { sistemática }\end{array}$ & 423855 & $\begin{array}{l}\text { Avaliar as tendências } \\
\text { da carga de câncer } \\
\text { entre pessoas com } \\
\text { HIV/AIDS nos } \\
\text { Estados Unidos entre } \\
1991 \text { e } 2005 \text {, usando } \\
\text { dados nacionais de } \\
\text { prevalência de AIDS e } \\
\text { taxas representativas } \\
\text { de câncer. Também } \\
\text { estimar o ônus do } \\
\text { câncer em pessoas } \\
\text { vivendo com HIV, } \\
\text { mas sem AIDS entre } \\
\text { 2004 e 2007, usando } \\
\text { dados recentes mais } \\
\text { limitados de } 34 \\
\text { estados dos EUA. }\end{array}$ & $\begin{array}{l}\text { Apesar da diminuição ao longo } \\
\text { dos anos do risco de cânceres } \\
\text { definidores da AIDS, SK e LNH } \\
\text { continuam sendo as neoplasias } \\
\text { mais comuns na população } \\
\text { vivendo com HIV/aids nos } \\
\text { Estados Unidos. Além disso, a } \\
\text { carga de cânceres não definidores } \\
\text { da AIDS aumentou entre as } \\
\text { pessoas que vivem com HIV nos } \\
\text { EUA. Este aumento foi } \\
\text { impulsionado pelo crescimento e } \\
\text { envelhecimento da população } \\
\text { HIV+. }\end{array}$ & A & I \\
\hline $\begin{array}{l}\text { Álvarez- } \\
\text { Guevara et } \\
\text { al., } 2017\end{array}$ & $\begin{array}{l}\text { Colômbi } \\
\mathrm{a}\end{array}$ & Transversal & 139 pacientes & $\begin{array}{lr}\text { Determinar } & \text { a } \\
\text { prevalência } & \text { de } \\
\text { neoplasias definidoras } & \text { em pacientes adultos } \\
\text { com HIV do Instituto } \\
\text { Nacional de } \\
\text { Cancerologia por um } \\
\text { período de } 7 \text { anos. }\end{array}$ & $\begin{array}{l}\text { Houve uma predominância do } \\
\text { sexo masculino }(84,2 \%) \text {. } \\
\text { O tipo mais comum de neoplasia } \\
\text { foi o LNH, seguido pelo SK, e, } \\
\text { por fim, o câncer invasivo do colo } \\
\text { do útero. } \\
\text { Foi observada uma predominância } \\
\text { de malignidades definidoras no } \\
\text { grupo de pacientes vivendo com } \\
\text { HIV. }\end{array}$ & $\bar{A}$ & VI \\
\hline
\end{tabular}

Legenda: NIC: Neoplasia intraepitelial cervical; HPV: Papilomavírus Humano; ADCs: Cânceres definidores de AIDS; NADCs: Cânceres não definidores de AIDS; CEC: Carcinoma espinocelular; HAART: Terapia antirretroviral altamente ativa; SK: Sarcoma de Kaposi; LNH: Linfoma não-Hodgkin; LH: Linfoma de Hodgkin. Fonte: Autores, (2021).

\section{Discussão}

Segundo Nahas et al. (2011) o carcinoma espinocelular (CEC) do canal anal é doença que atinge os adultos de meia idade. Atinge mais os homens e entre os homens que fazem sexo com homens a incidência atinge 35 por 100.000 habitantes, sendo que os indivíduos vivendo com HIV têm esse risco duplicado. De fato, é um grande fator de risco a soropositividade no desenvolvimento do CEC anal nos pacientes infectados por HPV.

Algo semelhante pode ser visto no estudo de Vissoto, Siqueira e Carvalho (2018), onde foi possível observar um aumento da incidência do CEC nos últimos 30 anos, especialmente em homens e indivíduos HIV positivos. A idade média de apresentação da doença é entre 50 e 60 anos nos Estados Unidos. É fundamental pontuar que o carcinoma de canal anal é o câncer mais comum em pacientes que vivem com HIV nos Estados Unidos e o terceiro mais comum na França, sendo o risco de adquiri-lo, para quem é HIV positivo, 79 vezes maior do que na população geral francesa (Hleyhel, 2014). 
O Sarcoma de Kaposi (SK), o linfoma não Hodgkin (LNH) e o carcinoma do colo uterino são as neoplasias mais frequentes em pacientes com HIV/AIDS. São consideradas doenças definidoras da AIDS. Das 261 necropsias realizadas em pacientes HIV positivos, 191 (73,2\%) eram do sexo masculino. A idade média foi de 35,3 $\pm 10,7$ anos, variando de 16 a 69 anos. Neoplasias foram encontradas em 58 (22,2\%) das 261 necropsias. SK foi encontrado em 27\% dos casos avaliados e LNH em 21,9\% e, no segundo, 38,9\% apresentaram SK e LNH em 32,6\% (Micheletti et al., 2011). Nos estudos de Silverberg et al. (2009) e Shiels et al. (2011), resultados semelhantes foram encontrados.

Essas neoplasias ganham destaque por se apresentarem mais frequentemente em pacientes vivendo com HIV quando comparados com a população em geral. O SK foi a primeira doença oportunista reconhecida em associação com o HIV e ainda é a neoplasia mais frequente relacionada à AIDS. No estudo de Tancredi et al. (2017) dentre os 3.557 casos de AIDS, 213 (6\%) apresentavam SK, sendo que 95,3\% eram do sexo masculino. Esses resultados reforçam a existência de uma relação entre 3 pontos chaves: os pacientes HIV positivo, a presença do SK e o sexo masculino.

No estudo de Saldarriaga-Cantillo et al. (2012) foi realizado uma análise do período de 1963 a 2007 e, com relação aos novos casos de SK entre os residentes de Cali, num montante de 349 indivíduos: 306 (87,7\%) dos indivíduos com SK eram do sexo masculino, valendo ressaltar que esse tipo de tumor não foi observado em menores de 20 anos. Essa discrepância no envolvimento de gênero é possivelmente influenciada por fatores de proteção presentes nas mulheres, fato possivelmente relacionados aos hormônios femininos, que poderiam diminuir o risco de desenvolver SK.

Nos EUA verificou-se que existiam 2.156 casos de LNH (4,3\%) dentre 51.033 pessoas com AIDS em sete regiões. Na Itália, um dos países com maior prevalência de AIDS na Europa, foi descrito que $8 \%$ do total de LNH se correlacionavam a AIDS (Dal Maso et al., 2001). O estudo de Raffetti et al. (2015), evidenciou resultados semelhantes, o LNH foi também o câncer mais encontrado, presente em $27 \%$ dos pacientes que tinham alguma neoplasia e eram HIV positivo, seguido pelo SK, com 24,7\%. No Brasil, os dados do Ministério da Saúde indicaram no período de 1998 a junho de 2000 , para 2.062 casos, foram identificados 1.521 LNH sistêmicos e 541 LNH primários do SNC (Ministério da Saúde, 2000). No estudo de Freitas et al. (2017), realizado no Brasil, o Linfoma não Hodgkin esteve presente em 37\% dos pacientes, caracterizando-se como o mais prevalente, seguido pelo Sarcoma de Kaposi com 14,8\%, validando a importância desses dois tipos de neoplasia nos pacientes HIV positivos.

Segundo Strickler et al. (2005), a incidência de câncer de colo de útero em mulheres vivendo com HIV/AIDS é dez vezes maior do que em mulheres não infectadas. Nesse estudo, realizado com cerca de 6 mil mulheres, sendo metade delas vivendo com AIDS, evidenciou uma relação entre a imunossupressão e o risco de desenvolvimento do HPV. No entanto, ainda foi evidenciado que essa relação não é igual para todos os tipos do vírus HPV. O tipo que está relacionado à maioria dos cânceres de colo do útero, o HPV-16, é de fato, o menos afetado pela diminuição da imunidade, o que sugere que este vírus já tem uma habilidade inata para evitar os efeitos do sistema imunológico humano.

O estudo de Ceccato Junior et al. (2015) também deixa clara a relação citada acima entre HPV e a imunossupressão, salientando ainda que no grupo de indivíduos vivendo com HIV a chance de haver uma infecção por múltiplos tipos do HPV é 7,8 vezes maior que na população HIV negativa, o que corrobora com a elevada incidência de câncer na população que vive com HIV.

O linfoma não-Hodgkin, o sarcoma de Kaposi e o câncer cervical invasivo apresentam os maiores índices de prevalência como as neoplasias mais frequentes em indivíduos vivendo com HIV, sendo, portanto, consideradas definidoras da Síndrome da Imunodeficiência Humana Adquirida (AIDS).

Álvarez-Guevara et al. (2017) encontraram neoplasias definidoras de AIDS em 91 pacientes, o que corresponde a $65,5 \%$ da amostra total. No estudo, foi percebido que o linfoma não-Hodgkin é a malignidade definidora predominante $(\mathrm{n}=$ 46), seguida pelo sarcoma de Kaposi $(n=42)$ e o câncer invasivo do colo do útero $(n=3)$. As neoplasias não definidoras foram 
encontradas em 34,5\% dos indivíduos $(n=48)$ e as mais frequentes foram o câncer anal $(\mathrm{n}=7)$, o linfoma de Hodgkin $(\mathrm{n}=7)$ e o câncer não invasivo do colo do útero $(\mathrm{n}=6)$. Já em Silverberg et al. (2009), Shiels et al. (2011), Hleyhel et al. (2014), Raffetti et al. (2015), Nagata et al. (2018), o tipo mais encontrado foi o câncer de fígado, cujo risco em indivíduos HIV positivos foi 11 vezes maior se comparado com a população geral.

O linfoma de Hodgkin também foi citado, no estudo de Hleyhel et al. (2014), como uma das neoplasias principais, sendo o segundo em número de casos com 535 dentre 84.504 (0,63\%) notificações. Em Silverberg et al. (2009), esteve atrás apenas do câncer anal, com 47 casos dentre os 773 pacientes do montante (6,08\%) e, por fim, no estudo de Shiels et al. (2011), foi responsável por 2004 casos dentre os 79.657 (2,51\%) avaliados. Vale salientar alguns que as neoplasias do pulmão e anal também foram consideradas relevantes. é relavante pontuar também que a neoplasia do estômago foi mais evidente nas populações asiáticas, principalmente no Japão, em que esteve atrás apenas do colorretal, algo justificado pela maior prevalência de infecção por H. pylori na região (Nagata et al., 2018).

Em relação às características sociodemográficas é importante destacar no estudo de Álvarez-Guevara et al. (2017), a predominância do sexo masculino $(84,2 \%)$ na população em idade ativa.

Um ponto curioso é que o estudo realizado por Neto et al. (2012) aparece com resultados divergentes dos estudos acima. Segundo os seus achados, quase metade dos casos de câncer eram neoplasias que não definem a AIDS, normalmente apresentando resultados semelhantes entre indivíduos HIV positivos ou não. Não foi possível estabelecer uma diferença significativa entre os dois grupos, provavelmente por causa do pequeno número de casos no montante do estudo.

Através dos estudos de Junior et al. (2016), que abordam a relação entre a neoplasia intraepitelial cervical (NIC) e pacientes HIV positivos e negativos, ficou evidente que a presença do HIV é responsável por um recrudescimento relevante da NIC, sendo encontrados valores de incidência 6 vezes maior em mulheres vivendo com HIV do que nas que não vivem, provavelmente devido à chance 7,8 vezes maior de terem uma infecção múltipla de diferentes subtipos de HPV e terem uma prevalência de subtipos de alto risco do Papilomavírus Humano.

No estudo de Silverberg et al. (2009), foi possível constatar que a presença do HIV não só aumenta significativamente a presença do câncer intraepitelial cervical, como torna possível sua presença mesmo sem ter contraído o HPV, pelo fato do HIV suprimir o sistema imunológico, pessoas portadoras do vírus tem uma capacidade reduzida de controlar as infecções e, assim, de combater adequadamente o processo viral oncogênico. Algo semelhante ocorre no estudo de Nagata et al. (2018), mas com relação à maior incidência de câncer de estômago no Japão, em comparação com os países ocidentais. Nesse caso, o estudo sugere que a menor imunidade encontrada em pacientes vivendo com HIV pode resultar em um recrudescimento da exposição a infecções e gastrites graves, o que leva a um risco aumentado de câncer de estômago, já que a função imunológica adequada é necessária para evitar uma infecção por Helicobacter pylori e a inflamação associada.

Mesma observação foi feita no estudo de Shiels et al. (2011), que, ao avaliar o câncer anal, de fígado e linfoma de Hodgkin, que são sempre associados à coinfecção (HPV para câncer anal, vírus da hepatite B e C para câncer de fígado e vírus Epstein-Barr para linfoma de Hodgkin) percebeu que, devido à presença do HIV, o risco de surgir esses cânceres aumenta pela

Em relação aos aspectos étnicos, existem poucos estudos que o abordam. No estudo de Freitas et al. (2017) foi possível perceber que a raça branca é mais prevalente, dos 27 indivíduos vivendo com HIV e portadores de algum tipo de câncer, 19 se identificaram como sendo da raça branca, 01 da negra e 07 da parda. Já no estudo de Fedrizzi et al. (2011), das 14 mulheres pesquisadas, 13 eram brancas. O estudo de Silverberg et al. (2009) a coorte de pacientes HIV negativos teve menos negros e brancos, porém mais asiáticos e hispânicos quando comparados à coorte dos indivíduos HIV positivos, entre aqueles com raça/etnia conhecida. É importante destacar novamente que houve uma grande dificuldade para encontrar dados relacionando questão étnica com neoplasias em HIV positivos, é possível identificar o sexo predominante e a idade, contudo, há pouco enfoque na raça/etnia. 


\section{Conclusão}

Os estudos desta revisão mostram que de fato o sarcoma de Kaposi (SK), o linfoma não Hodgkin (NHL) e o carcinoma do colo uterino são as neoplasias mais frequentes em pacientes vivendo com HIV/AIDS. Vale destacar que o sexo masculino foi o mais acometido e a raça caucasiana foi a predominante. Além disso, é importante pontuar também que apesar de não serem os mais prevalentes, os cânceres não definidores de AIDS (CNDA) estão em um número notável de pessoas e, por não serem associados diretamente à síndrome, pode haver uma demora no diagnóstico e, assim, acarretar num agravamento do quadro de saúde do paciente, portanto, sugerimos que haja um cuidado maior no diagnóstico diferencial, considerando sempre a possibilidade de CNDA.

Um ponto forte do estudo foi a revisão de artigos de países distintos, apresentando diferentes sistemas de saúde, permitindo uma análise mais detalhada sobre o tema. As dificuldades encontradas foram os poucos estudos recentes abordando a epidemiologia de neoplasias em pessoas vivendo com HIV/AIDS, diante disso, estudos longitudinais com essa temática são necessários.

Seria de grande valia trabalhos futuros com o foco em estabelecer uma relação entre fatores epidemiológicos de neoplasias em pessoas vivendo com HIV/AIDS, a fim de correlacionar melhor os fatores sociais às cepas oncogênicas, destacamos a importância de se averiguar a questão racial como influência, já que há uma escassez de dados sobre esse fator epidemiológico.

\section{Referências}

Alvarez-Guevara, D. et al. (2017). Prevalence of defining malignancies in adult patients with HIV/AIDS in the National Cancer Institute of Colombia. 20072014. Rev. fac. med., v. 65 (3), 397-402.

Bosch, F. X. et al. (2002). The causal relation between human papillomavirus and cervical cancer. J. Clin Pathol. 55, 244-65.

Burd, E. (2003). Human Papillomavirus and cervical cancer. Clinical Microbiology Reviews. 16, n.1, 1-17.

Caetano, J. A. M. (1991). Aspectos imunológicos pertinentes da infecção por HIV. Acta Médica Portuguesa. 4 supl. 1 Portugal.

Ceccato Junior, B. P. V. et al. (2015). Prevalência de infecção cervical por papilomavírus humano e neoplasia intraepitelial cervical em mulheres HIVpositivas e negativas. Rev. Bras. Ginecol. Obstet. 37 (4), 178-185.

Dalmaso, L., Serraino, D., \& Franceschi, S. (2001). Epidemiology Of AIDS - related tumours in developed and developing countries. Eur. J. Cancer. 37, $1188-1201$

Freitas, J. B. et al. (2017). Perfil epidemiológico dos pacientes infectados pelo hiv com e sem câncer em um hospital público na baixada santista - SP - Brasil. Revista UNILUS Ensino e Pesquisa. 14 (34), 17.

Hleyhel, M. et al. (2014). Risk of non-AIDS-defining cancers among HIV-1-infected individuals in France between 1997 and 2009: results from a French cohort. AIDS. 10; 28(14), 2109-18.

Junior, B. P. V. C. et al. (2016). Incidence of Cervical Human Papillomavirus and Cervical Intraepithelial Neoplasia in Women with Positive and Negative HIV Status. Rev Bras Ginecol Obstet., 38(05), 231-238.

Micheletti, A. R. et al. (2011). Benign and malignant neoplasias in 261 necropsies for HIV-positive patients in the period of 1989 to 2008 . Rev. Inst. Med. trop. S. Paulo. 53(6), 309-314.

Ministério da Saúde (2000). Distribuição das doenças associadas, sinais e sintomas, no momento da notificação dos casos de AIDS entre indivíduos com 13 anos de idade ou mais, por período de diagnóstico. Brasil, 1983-2000. Coordenação Nacional de DST e AIDS. AIDS-Bol. Epidemiol. $13,48$.

Nagata, N. N. T. et al. (2018). Increased risk of non-AIDS-defining cancers in Asian HIV-infected patients: a long-term cohort study. BMC Cancer. 6;18(1), 1066 .

Pinto Neto, L. F. S. et al. (2012). Malignancies in HIV/AIDS patients attending an outpatient clinic in Vitória, State of Espírito Santo, Brazil. Rev. Soc. Bras. Med. Trop. 4(6), 687-690.

Portugal, T. G. A. (2004). Estudo comparativo entre linfomas não hodgkin em indivíduos hiv-positivos e hiv-negativos em Salvador, Bahia. Associação com o vírus epstein-barr e classificação segundo a OMS-2001. Universidade Federal da Bahia. Dissertação de mestrado. 119 f.

Robbins, C. (2010). Bases Patológicas das Doenças. 8 ed. Rio de Janeiro: Elsevier.

Raffetti, E. et al. (2015). Cancer incidence and mortality for all causes in HIV-infected patients over a quarter century: a multicentre cohort study. BMC Public Health. 15, 235. 
Research, Society and Development, v. 10, n. 11, e48101119240, 2021

(CC BY 4.0) | ISSN 2525-3409 | DOI: http://dx.doi.org/10.33448/rsd-v10i11.19240

Saldarriaga-Cantillo, A. et al. (2012). Epidemiological surveillance of the HIV/AIDS complex through the analysis of trends in the incidence of Kaposi's sarcoma in Cali, Colombia. Colomb. Med. 43(4), 273-280.

Sardinha, R. et al. (2015). HIV and HPV infection - clinical relevance, Acta Obstet Ginecol Port. 9(3), 241-249.

Strickler, H. D. et al. (2005). Natural history and possible reactivation of human papillomavirus in human immunodeficiency virus-positive women. $J$ Natl Cancer Inst. 20;97(8), 577-86.

Silverberg, M. J. et al. (2009). HIV infection and the risk of cancers with and without a known infectious cause. AIDS. 13;23(17), 2337-45.

Shiels, M. S. et al. (2011). Cancer burden in the HIV-infected population in the United States. J Natl Cancer Inst.

Tancredi, M. V. et al. (2017). Prevalência de sarcoma de Kaposi em pacientes com aids e fatores associados, São Paulo-SP, 2003-2010. Epidemiol. Serv. Saúde. 26(2), 379-387.

Vissoto, E. F., Siqueira, G. S. M., \& Carvalho; A. L .L. (2018). Câncer de canal anal. Diretrizes oncológicas. 20, 289-296. 